\title{
EFFECT OF GYMNEMA SYLVESTRE METHANOLIC EXTRACT ON PANCREATIC PUTRESCINE LEVELS AGAINST ALLOXAN-INDUCED DIABETIC RATS
}

\author{
JOTHI MUNIYANDI $\mathbf{M}^{1}$, BENNO SUSAI VIJAYAKUMAR A ${ }^{2 *}$
}

${ }^{1}$ Department of Biochemistry and Biotechnology, Sourashtra College (Autonomous), Madurai, Tamil Nadu, India. ${ }^{2}$ Department of Biochemistry, St. Joseph's College (Autonomous), Tiruchirappalli, Tamil Nadu, India. Email: bennosusai@gmail.com

Received: 26 June 2018, Revised and Accepted: 21 September 2018

\section{ABSTRACT}

Objective: Gymnema sylvestre, a rare herb with significant medicinal values widely used as a naturopathic treatment for diabetes. This study demonstrates the antidiabetic potential and changes in the levels of pancreatic putrescine in G. sylvestre treated experimental rat models.

Methods: Phytochemical analysis was carried out for methanolic leaf extract of G. sylvestre (GSME). Further, antidiabetic property and putrescine levels in alloxan-induced diabetic Wister albino rats were analyzed by high-performance liquid chromatography method.

Results: The GSME (500 mg/kg b/w) was administered daily up to 15 days in diabetic rats against standard drug metformin (500 mg/kg b/w). At the end of the experiments, the increased body weights were noted in the diabetic control groups, while there was reduction in blood glucose level, total protein, liver glycogen, glutathione, glutathione peroxidase, and blood catalase, respectively.

Conclusion: GSME at the dose of (500 mg/kg b/w) brings about significant beneficial effects in various physiological parameters and level of putrescine altered during diabetic manifestations, and these effects are quite comparable with the standard drug, metformin.

Keywords: Alloxan, Gymnema sylvestre, Metformin, Putrescine, High-performance liquid chromatography, Wister albino rats

(C) 2019 The Authors. Published by Innovare Academic Sciences Pvt Ltd. This is an open access article under the CC BY license (http://creativecommons. org/licenses/by/4. 0/) DOI: http://dx.doi.org/10.22159/ajpcr.2019.v12i1.28117

\section{INTRODUCTION}

Diabetes mellitus (DM) is a chronic condition characterized by high blood glucose (hyperglycemia) due to defect in insulin secretion, insulin action, or both. The number of patients suffering from DM is increasing at alarming rate due to changes in lifestyle, stress, obesity, and aging in general populations, worldwide [1]. It has been estimated as more than 300 million peoples would have the disorder by 2025 [2]. At present, India is one of the few countries having a population of $<60$ million diabetic patients [3].

Increase in the number of diabetic patients, high cost for medical treatments, unsatisfactory treatment response, and mistrust of people in nowaday's health-care facilities signifies that modern medicinal systems are still incomplete. These factors are the major reasons for the continuous to trust on traditional medical practices such as Siddha, Ayurveda, and Unani [4].

The ethnobotanical reports state that plants represent a major potential source of drugs for dealing with hyperglycemia. Gymnema sylvestre is a large woody climber, belongs to the family Asclepiadeceae. It is widely distributed throughout in India, Sri Lanka, Malaysia, Vietnam, and South Africa [5]. G. sylvestre is one of the important antidiabetic medicinal plants. Gymnemic acid is an active ingredient extracted from leaves which are used widely as antidiabetic agent. It has been reported that the $G$. sylvestre possess antibacterial, antioxidant, anticancer, and wound healing medicinal properties [6]. The phytochemicals in leaf extract were analyzed and bioactive constituents were found to be a mixture of diverse phytomolecules such as gymnemic acids, gymnemosides, gymnemasaponins, gurmarin, gymnemanol, stigmasterol, d-quercitol, $\beta$ amyrin-related glycosides, anthraquinones, lupeol, hydroxycinnamic acids, and coumarols group [7].

Putrescine is one of the polyamines present in almost all living cells. However, low putrescine levels are considered physiologically important in maintaining the normal growth and function of cells and also act as a precursor of spermidine and spermine, which are consequently playing an important metabolic role [8]. It is an aliphatic cation present at millimolar concentration in pancreatic $\beta$-cells [9]. Hence, in the present study, G. sylvestre methanolic leaf extract (GSME) was analyzed for phytochemical constituents and the effects of GSME on the alloxan-induced diabetic Wister albino rats, on its blood glucose, body weight, and physiological effects on pancreatic putrescine levels.

\section{METHODS}

Plant collection and extract preparation

Leaves of $G$. sylvestre were collected from Narthamalai hills, Pudukkottai district, Tamil Nadu. The plant material was identified and authenticated by Dr. K.M. Rajasekaran, Professor and Head, Department of Botany, The Madura College, Madurai, India. The leaves were washed in running water, air dried under shade and powdered. $50 \mathrm{~g}$ of powdered leaf material was exhaustively extracted with methanol. To obtain the GSME, the solvent was drained through Whatman No. 1 filter paper and was concentrated using rotary vacuum dryer. Thus, the obtained GSME was stored at $-20^{\circ} \mathrm{C}$ for further experiments.

\section{Maintenance of experimental animals}

Adult Wister albino rats of body weight (90 g-120 g) were collected and acclimatized in polypropylene cages and fed with a standard diet. They were housed to an alternating $12 \mathrm{~h}$ dark and $12 \mathrm{~h}$ light cycle. The experimental protocol was approved by the Institutional Animal Ethics Committee (IAEC).

\section{Induction of diabetes in rats}

The rats were injected intraperitoneally with freshly prepared alloxan monohydrate (Sigma, St. Louis, MO, USA) dissolved in sterile saline at a dose of $120 \mathrm{mg} / \mathrm{kg} \mathrm{b} / \mathrm{w}$ in $0.1 \mathrm{M}$ citrate buffer. Blood samples were collected before the administration of alloxan. After 5 days of 
alloxan injection, rats with glucose range from 200 to $300 \mathrm{mg} / \mathrm{dl}$ were considered as diabetic and were separated and divided into different groups containing six rats per group for the antidiabetic study.

\section{Antidiabetic activity of GSME}

Adult Wister albino diabetic rats were treated with GSME for 15 days. Throughout the study period, all animals had free access to standard diet and water. On the $15^{\text {th }}$ day, all the overnight fasted rats were killed by cervical dislocation and blood samples were collected for biochemical studies using cardiac puncture. Liver and pancreas were dissected out, washed in ice-cold saline, and immediately stored in deep freezer at $-80^{\circ} \mathrm{C}$ for further studies

\section{Various experimental groups}

Experimental animals were divided into four different groups (each group six rats)

Group I: Control rats received saline and fed on normal diet.

Group II: Diabetic control rats received saline and fed on normal diet. Group III: Diabetic rats received a dose of GSME $(500 \mathrm{mg} / \mathrm{kg} \mathrm{b} / \mathrm{w})$ and Group IV: Diabetic rats received a dose of metformin $(500 \mathrm{mg} / \mathrm{kg} \mathrm{b} / \mathrm{w})$

\section{Biochemical investigation}

Qualitative phytochemical analysis was carried out by Brinda et al. method [10], estimation of blood glucose levels was determined by the O-toluidine method [11], total serum protein was estimated by Lowry's method [12], and liver glycogen content was determined by the method of Hassid and Abraham [13].

\section{Antioxidant activity}

Reduced glutathione (GSH), blood glutathione peroxidase (GPx), and blood catalase (CAT) antioxidant activities were carried out by the standard methods [14-16]. Putrescine was measured by a modified high-performance liquid chromatography (HPLC) method [17].

\section{Statistical analysis}

One-way analysis of variance statistics is a software package 17 and was used to compare the mean values of each treatment. Significant differences between the means of parameters were determined using the Dunnett's multiple range test $(\mathrm{p}<0.05)$ comparing between the groups control versus treated.

\section{RESULTS AND DISCUSSION}

\section{Phytochemical studies}

Phytochemical investigation is one of the tools for the standardization of the herbal drug. In this study, GSME was subjected to qualitative investigation and the results showed the presence of phytoconstituents such as alkaloids, triterpenoids, reducing sugar, saponin, and

Table 1: Effect of GSME on in vivo biochemical parameters in diabetic rats.

\begin{tabular}{llll}
\hline Group & $\begin{array}{l}\text { Blood } \\
\mathbf{m g} / \mathbf{d l}\end{array}$ & $\begin{array}{l}\text { Protein } \\
\text { g/dl }\end{array}$ & $\begin{array}{l}\text { Liver glycogen } \\
\text { g/dl }\end{array}$ \\
\hline Control & $98.80 \pm 11.88$ & $7.3 \pm 0.45$ & $1.23 \pm 0.086$ \\
Diabetic & $197 \pm 19.84$ & $5.3 \pm 0.80$ & $0.40 \pm 0.71$ \\
GSME treated & $117.36 \pm 3.33$ & $6.8 \pm 0.63$ & $1.170 \pm 0.066$ \\
Metformin treated & $109.30 \pm 9.21$ & $6.3 \pm 15$ & $1.186 \pm 1.44$ \\
\hline
\end{tabular}

tannins. Similarly, Srinivasan and Kumaravel [18] reported that the ethanolic extract of $G$. sylvestre (GSME) contains terpenes, fatty acids, alcohols, amines, and vitamins. It was also suggested that all these phytoconstituents have various pharmacological activities such as antiinflammatory, antiallergic, antioxidant, antidiabetic, antimicrobial, and many more.

\section{Antidiabetic activity}

\section{Effect of GSME on blood glucose levels}

Blood glucose levels of the alloxan administrated rats are significantly higher than the normal rats. In alloxan $(120 \mathrm{mg} / \mathrm{kg})$-induced rats, the blood glucose level significantly raised from 98 to $197 \mathrm{mg} / \mathrm{dl}$. Posttreatment with GSME decreased the blood glucose levels from 197 to $109 \mathrm{mg} / \mathrm{dl}$, whereas metformin was used as positive control for this study (Table 1). This result corroborates well with the findings of Wasfi [19], where the alloxan-induced diabetic laboratory rats showed a significant decrease in blood glucose level in the experimental group treated with methanol extract of cinnamon and metformin drug compared with their control group (normal saline).

\section{Effect of GSME on total protein levels}

Alloxan-induced diabetic rats were found to have decreased total protein $(5.3 \pm 0.80)$ level in serum as compared to control $(97.3 \pm 0.45)$. Administration of GSME to the diabetic rats resulted in a significant increase in the level of serum total protein $(6.8 \pm 0.63)$ (Table 1).

\section{Effect of GSME on liver glycogen contents}

Significant reduction was noted in the level of glycogen in liver in diabetic groups with respect to control. After oral treatment of GSME to the diabetic animals, there was a significant recovery when compared to diabetic group. Glycogen $(1.170 \pm 0.066)$ levels in above-mentioned tissues were resorted to the control level after supplementation of GSME (Table 1).

\section{Effect of GSME on non-enzymatic antioxidant levels}

The GSH levels in normal rats were $25.3 \pm 0.26 \mathrm{mg} / \mathrm{dl}$. In alloxan-treated diabetic rats, the GSH levels decreased significantly $(14.2 \pm 0.61 \mathrm{mg} / \mathrm{dl})$. GSME-treated rats showed a significant increase in the blood GSH levels than non-diabetic rats (Table 2).

\section{Effect of GSME on enzymatic antioxidant levels}

The activity of serum enzymes CAT $(5.60 \pm 0.29)$ and GPx $(8.3 \pm 0.41)$ significantly increases in diabetic rats when compared to normal controls. Oral administration of GSME for 16 days significantly restored the enzyme levels to near normal in diabetic rats (Table 2).

\section{Effect of GSME on Putrescine levels}

Putrescine is one of the polyamines present in the pancreatic tissue. The putrescine is necessary for the production of proinsulin biosynthesis [20]. The HPLC of alloxan-induced diabetic rat's pancreatic tissue represents the putrescine level as $47.807 \mu \mathrm{g} / \mathrm{g}$. The HPLC of alloxan-induced diabetic rat treated with GSME's pancreatic tissue showed $60.938 \mu \mathrm{g} / \mathrm{g}$ of putrescine level. The treatment of GSME with alloxan-induced diabetic rat's helps to increase the level of polyamine like putrescine (Figs. 1 and 2).

Table 2: Effect of GSME on in vivo antioxidant parameters in diabetic rats

\begin{tabular}{llll}
\hline Group & Catalase $\mathbf{~ m g / d l}$ & Glutathione peroxidase $\mathbf{~ m g / d l}$ & Reduced glutathione $\mathbf{~ m g} / \mathbf{d l}$ \\
\hline Control & $5.84 \pm 0.49$ & $9.96 \pm 0.67$ & $25.3 \pm 0.26$ \\
Diabetic & $4.36 \pm 0.71$ & $5.4 \pm 0.47$ & $14.2 \pm 0.61$ \\
GSME treated & $5.60 \pm 0.29$ & $8.3 \pm 0.41$ & $22.6 \pm 0.23$ \\
Metformin treated & $5.21 \pm 0.22$ & $8.72 \pm 0.45$ & $20.73 \pm 0.65$ \\
\hline
\end{tabular}

GSME: Methanolic leaf extract of Gymnema sylvestre 


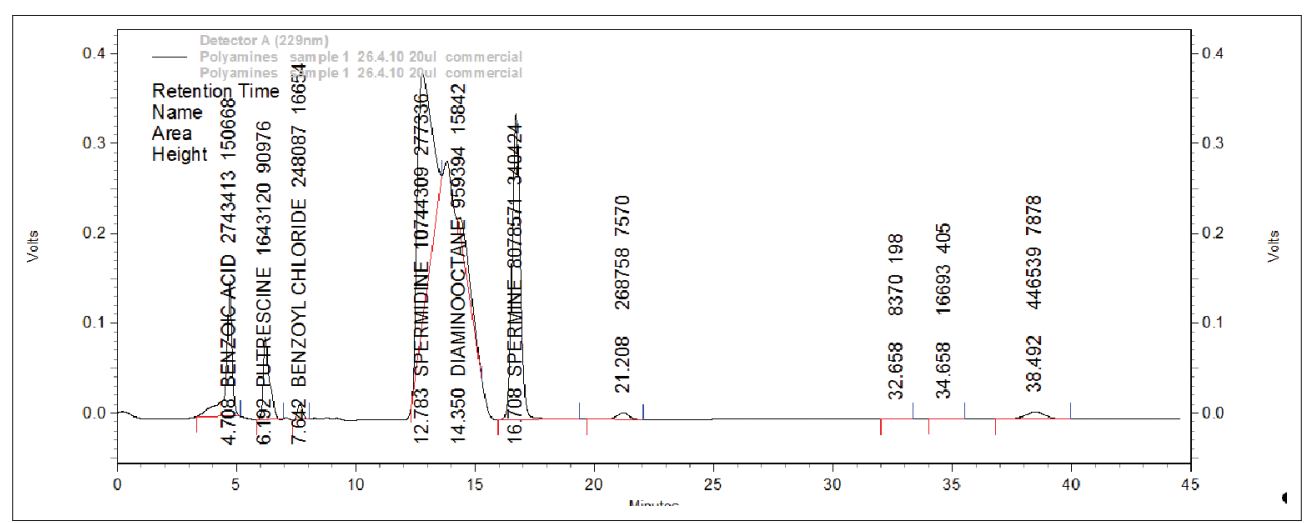

Fig. 1: High-performance liquid chromatography of pancreatic tissue from alloxan-induced diabetic rat

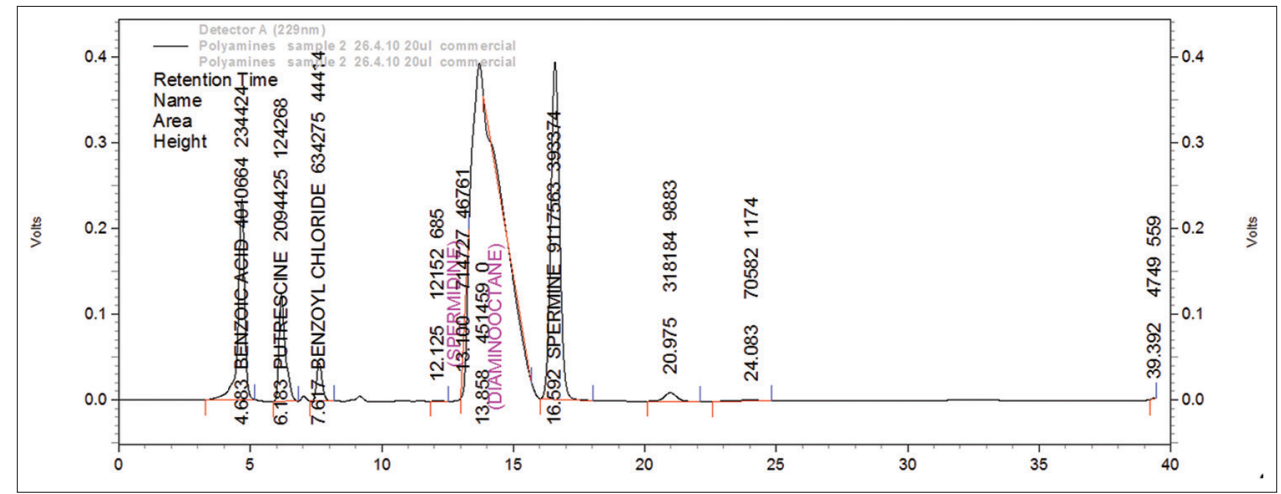

Fig. 2: High-performance liquid chromatography of pancreatic tissue from alloxan-induced diabetic rat treated with methanolic leaf extract of Gymnema sylvestre

\section{CONCLUSION}

In this experiment, the antidiabetic efficacy of GSME on alloxan-induced diabetic rats was studied. To the best of authors' knowledge, this is the first study ever done on the levels of putrescine in pancreatic tissue of alloxan-induced diabetic rats. All the results indicated that increase in the level of putrescine in diabetic group enhances the production of proinsulin and reduces the diabetes. This shows a promising result in the treatment of insulin-dependent DM. A number of medicinal plants are available with antidiabetic property, the selected $G$. sylvestre leaf extract could contribute a lot to the world of diabetes with its antidiabetic property. Further, insight is needed to study elaborately the role of the above herbal plant in treating DM.

\section{AUTHORS' CONTRIBUTION}

Both the authors contributed equally to the work. Jothi Muniyandi M: Carried out the work and draft the manuscript. Benno Susai Vijayakumar A: Designed the experimental study, provided guidance, and reviewed the article draft.

\section{CONFLICTS OF INTEREST}

The authors have no conflicts of interest.

\section{REFERENCES}

1. Ani V, Naidu KA. Antihyperglycemic activity of polyphenolic components of black/bitter cumin Centratherum anthelminticum (L.) Kuntze seeds. Eur Food Res Technol 2008;226:897-903.

2. Bastaki S. Diabetes mellitus and its treatment. Int J Diabetes Metab 2005; 13:111-34.

3. Grover JK, Yadav S, Vats V. Hypoglycemic and antihyperglycemic effect of Brassica juncea diet and their effect on hepatic glycogen content and the key enzymes of carbohydrate metabolism. Mol Cell Biochem 2002;241:95-101.
4. Dimple, Kuma A, Kumar V, Tomer V. Traditional medicinal systems for treatment of diabtes mellitus: A review. Int J Pharm Pharm Sci 2018;10:7-17.

5. Paliwal R, Kathori S, Upadhyay B. Effect of Gurmar (Gymnema sylvestre) powder intervention on the blood glucose levels among diabetics. Ethno-Med 2009;3:133-5.

6. Kadlidass C, Mohan VR. Pharmacognostical and phytochemical investigation studies on Gymnema sylvestre R.Br. Int J Biol Tech 2010;1:8-11.

7. Yoshikawa M, Murakami T, Kadoya M, Li Y, Murakami N, Yamahara J, et al. Medicinal food stuff. IX. The inhibitors of glucose absorption from the leaves of Gymnema sylvestre R.Br. (Asclepiadaceae): Structures of gymnemosides A and B. Chem Pharm Bull (Tokyo) 1997;45:1671-6.

8. Landete JM, Arena ME, Pardo I, Manca de Nadra MC, Ferrer S. The role of two families of bacterial enzymes in putrescine synthesis from agmatine via agmatine deiminase. Int Microbiol 2010;13:169-77.

9. Welsh N. A role for polyamines in glucose- stimulated insulin gene expression. Biochem J 1990;271:393-7.

10. Brinda P, Sasikala B, Purushothaman KK. Pharmacogenostic studies on Merugan kizhangu. Bull Med Eth Bott Res 1981;3:84-96.

11. Dubowaski KM. An o-toluidine method for body fluid glucose concentration. Clin Chem 1962;8:215-35.

12. Lowry OH, Rosenbrough NJ, Farr AL, Randall RJ. Protein measurements with Folin's regant. J Biol Chem 1951;193:265-75.

13. Hassid WZ, Abraham S. Chemical procedure for analysis of polysaccharides. In: Methods in Enzymology. Vol. III. New York, USA: Academic Press; 1957. p. 34-7.

14. Beutler E, Duron O, Kelly BM. Improved method for the determination of blood glutathione. J Lab Clin Med 1963;61:882-8.

15. Rotruck JT, Pope AL, Gather HE, Swanson AB, Hafeman DG, Hoekstra WG. Selenium: Biological role as a component of glutathione peroxidase. Science 1973;179:588-90.

16. Aebi H. Catalase in vitro. Method Enzymol 1984;105:121-6.

17. Verkoelen CF, Romijith JC, Schroeder FH, Van Schalkwiji WP, Splinter TA. Biomedical applications. J Chromatogr 1988;426:41-54.

18. Srinivasan K, Kumaravel S. Unraveling the potential phytochemical 
compounds of Gymnema sylvestre through GC-MS study. Int J Pharm Pharm Sci 2016;8:450-3.

19. Wasfi AH, Mohammed R. Comparison the effect of various Cinnamon plants extracts with Metformin in blood glucose level of Alloxan- induced diabetic laboratory rats. Kufa J Vet Sci 2011;2:91-101.

20. Sjoholm A, Arkhammar P, Berggren PO, Anderson A. Polyamines in pancreatic islets of obese-hyperglycemic mice of different ages. Am Physiol Cell Physiol 2001;280:317-23. 